\title{
Evaporation During Upwelling in Ghanaian Coastal Waters
}

\author{
R. W. Houghton \\ Dept. of Playsics, University of Ghana, Legon
}

17 April 1973

\section{ABSTRACT}

\begin{abstract}
To account for the salinity and temperature profiles measured during upwelling in Ghanaian coastal waters, it was proposed by Pople and Mensah that the upwelling is the result of local vertical mixing driven by evaporation. The results of heat budget calculations and direct evaporation measurements reported here do not support this novel hypothesis.
\end{abstract}

The investigation of the upwelling in Ghanaian coastal waters off Tema recently reported by Pople and Mensah (1971) contains some startling conclusions. Previous accounts of this upwelling (Ingham, 1970; Longhurst, 1964) are now seen to be unsatisfactory, because analysis of more extensive data (Ghana Fishery Research Unit, 1970; Bakun et al., 1973) did not find the expected correlation of the intensity and duration of the upwelling with meteorological factors such as insolation or surface wind. From recent measurements of temperature and salinity profiles, Pople and Mensah (1971) concluded that the upwelling is the result of evaporation which increases the surface salinity, initiating a thermohaline convective cell, and mixes a vertical column of water down to the ocean floor. Assuming no lateral advection of water, they then deduced the local evaporation rate from the measured change in salinity of the column of water.

The evaporation rates deduced in this way are extremely large. For the 3-day period from 14-17 July 1970 , they obtained an average evaporation of $1.3 \mu \mathrm{m}$ $\mathrm{sec}^{-1}$ which is equivalent to $113 \mathrm{~mm}$ day $^{-1}$. During one particular hour of 10 August 1970, the evaporation rate was as high as $14 \mu \mathrm{m} \mathrm{sec}-1$. When these are compared with the evaporation rates of $4-9 \mathrm{~mm} \mathrm{day}^{-1}$ measured by BOMEX (Holland, 1972) and the fact that the average daily insolation at Tema in July (400 cal $\mathrm{cm}^{-2}$ ) is equivalent to the latent heat of $7 \mathrm{~mm}$ of water, it is clear that this novel upwelling hypothesis leads to evaporation rates more than an order of magnitude larger than expected. The suggestion was made that specific local meteorological considerations which enhance evaporation might be responsible for this mixing mechanism. In this note we report the results of direct measurements of the evaporation in Ghanaian coastal waters during upwelling in order to test these ideas.

The evaporation hypothesis can be questioned for several reasons. Foremost is the impossibility of balancing the local heat budget. Evaporation of $340 \mathrm{~mm}$ of water during 14-17 July requires $84 \mathrm{~kJ} \mathrm{~cm}^{-2}$ of heat. The cooling of the ocean by $4 \mathrm{C}$ during this period could provide $50 \mathrm{~kJ} \mathrm{~cm}^{-2}$. Since the total solar radiation could not provide more than $5.8 \mathrm{~kJ} \mathrm{~cm}{ }^{-2}$, we are left with a deficit of $28 \mathrm{~kJ} \mathrm{~cm}^{-2}$ which cannot possibly be acquired by conduction from the air. It is even more difficult to reconcile the measurements reported on 10 August because on that day there was no cooling of the ocean water; thus, we must find another source of $55 \mathrm{~kJ}$ $\mathrm{cm}^{-2}$ of heat in a 6 -hr period to account for the alleged evaporation.

This past year, 1972, provided an ideal opportunity to study the local upwelling. The ocean temperature ranged between 29 and $27 \mathrm{C}$ from April through June. During the first week of July it dropped rapidly to $22 \mathrm{C}$ and ranged between 19 and $22 \mathrm{C}$ well into September.

In order to ascertain whether any peculiar atmospheric conditions exist along the Ghana coast that might affect local evaporation, the standard class A evaporation pan measurements at the Tema Meteorological Station situated $0.5 \mathrm{~km}$ from the coast were analyzed. No significant difference was found between the evaporation measured before and during the upwelling and the data were consistent with the bulk aerodynamic formulas fitted to other pan measurements (Penman, 1948; Rohwer, 1931).

However, in order to match as closely as possible the actual conditions in the ocean, critical measurements were made as follows: A container $60 \mathrm{~cm} \times 60 \mathrm{~cm}$ $\times 48 \mathrm{~cm}$, made of clear, 7 -mil polyethylene stretched over a light wooden frame and suspended in the ocean by a raft, was filled with sea water to the same level as the water outside the container. The top edge of the container was $8 \mathrm{~cm}$ above the water surface and the raft was carefully constructed to avoid any obstruction above that level. Evaporation was deduced from the changes of the salinity of the water in the container monitored in situ by two Hamon portable salinitytemperature probes. The salinity readings were accurate to $0.01 \%$ and the probes were calibrated immediately before and after each experiment to check for drifting. Atmospheric conditions were recorded by an Assman aspirated psychrometer and a Cassela cup counter anemometer mounted on the raft.

Water conditions inside the container very nearly matched those of the water in the ocean. No significant 
temperature difference was observed. The raft easily rode the large ocean swells while small wave motion was transmitted through the flexible polyethylene. Only when the wind exceeded $5 \mathrm{~m} \mathrm{sec}^{-1}$ did waves splash into the container. However, even with the greatest salinity difference between the ocean and container 2 liters of water would have to splash in to produce it change of $0.01 \%$ in the salinity of the water in the container. The raft was observed continuously to ensure that this did not happen.

Wind turbulence generated by the edges of the container will affect the evaporation from the container. From a series of measurements using identical but smaller containers it was found that the evaporation is maximum when the ratio of the container height above water to its width is approximately 0.5 ; at that time evaporation from the smaller container is approximately 1.5 times that from the largest container. The results of other pan evaporation research (Deardorff,
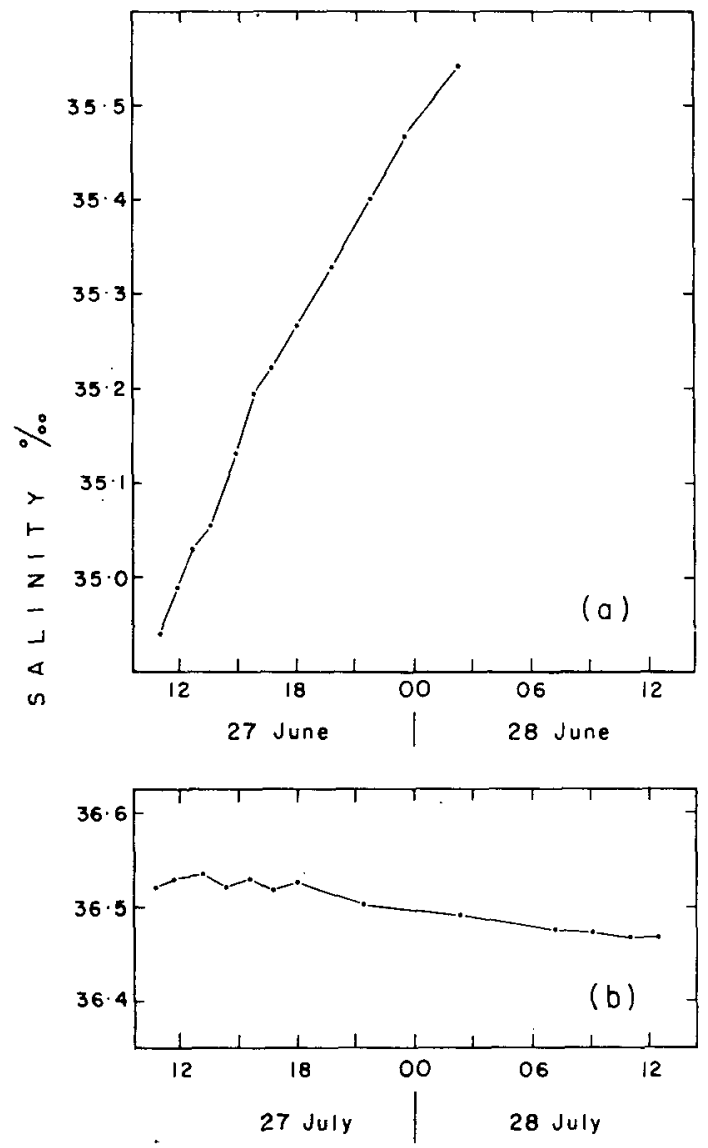

Fig. 1. Salinity of water in a container floating in Tema harbor as a function of time. Each point shown is the average of two separate salinity probe measurements and the lines are drawn merely to connect adjacent data points. The evaporation rate is proportional to the slope of the curve. Fig. 1a shows a typical measurement before the upwelling of 27 and 28 June with water temperature $t_{w}=27 \mathrm{C}$, average air temperature $t_{a}=26.5 \mathrm{C}$, and average vapor pressure difference $\left(e_{w}-e_{a}\right)=7 \mathrm{mb}$. Fig. $1 \mathrm{~b}$ shows the same measurement during the upwelling on 27 and 28 July with $t_{w}=20 \mathrm{C}, t_{a}=23 \mathrm{C}$ and $\left(e_{w}-e_{a}\right)=-4 \mathrm{mb}$.
1961 ; U. S. Geological Survey, 1954) indicate that the evaporation from our container should not be greater than twice that which occurs in open ocean waters.

Preliminary measurements during a period of no upwelling were taken from April through June, 1972. A typical result obtained on 27 and 28 June is shown in Fig. 1a where we plot the salinity as a function of time. The raft was located off the breakwater at Tema harbor approximately $0.7 \mathrm{~km}$ out into the ocean, protected slightly from the full ocean waves but with a fetch exceeding $300 \mathrm{~m}$. The average water temperature $\left(t_{w}\right)$ was $27 \mathrm{C}$, the average air temperature $\left(t_{n}\right)$ $26.5 \mathrm{C}$, and the average vapor pressure difference $\left(e_{w}-e_{a}\right) 7 \mathrm{mb}$. If we divide the measured evaporation by 2 we get an average evaporation rate of $5.5 \mathrm{~mm}$ day ${ }^{-1}$ which is within the range measured by BOMEX and is only slightly larger than calculations from bulk aerodynamic formulas (BOMEX, 1971; U. S. Geological Survey, 1954; Webb, 1960). In short, the local ocean evaporation showed no usual deviation from other well-established measurements.

During upwelling, the measurements were repeated at the same location on 27 and 28 July, the data being given in Fig. 1b. In sharp contrast to the previous case, instead of evaporation we observe a slight condensation throughout the night and into the next day. This is not surprising since the ocean is now so cold that with $t_{w}=20 \mathrm{C}$ and $t_{a}=23 \mathrm{C},\left(e_{w}-e_{a}\right)$ is approximately $-4 \mathrm{mb}$. On 10 August 1970 conditions were very similar with $e_{w}-e_{a} \approx-1 \mathrm{mb}$.

The observation that $e_{a}$ increases with height provides additional evidence of a flux of water vapor into the ocean. These measurements have been repeated several times further out at the entrance to the harbor in waters fully exposed to the ocean nearly $1 \mathrm{~km}$ from the coast; no significant evaporation was observed while the ocean temperature was below $22 \mathrm{C}$.

To summarize, evaporation measurements taken from a land-based pan and a floating container in the harbor reveal that evaporation rates along the Ghana coast do not deviate significantly from the bulk aerodynamic predictions. It seems clear, therefore, that evaporation cannot be the mechanism for the local upwelling.

During the upwelling the cold water is confined to a narrow belt along the coast, while $100 \mathrm{~km}$ from the coast the ocean temperatures range near 25C. In Fig. 2 we show the water and air temperatures taken on a transect south of Tema during the upwelling (data kindly supplied by Mr. Enoch Opey, Fishery Research Unit). Because of the cooling of the surface air blowing in from the southwest and the change in sign of $\left(e_{w}-e_{a}\right)$ approximately $16 \mathrm{~km}$ from the coast, we expect stable conditions along the coast.

One expects that ocean currents play a role in the local upwelling. However, recent current measurements by the Ghana Fishery Research Unit (1973) indicate many reversals in the direction of the local ocean cur- 

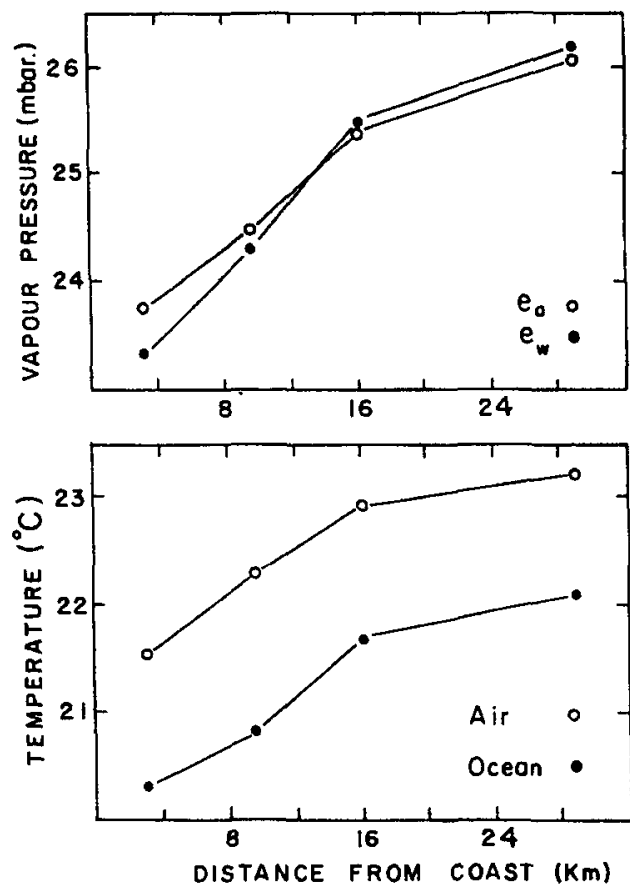

Fig. 2. Temperature and vapor pressure as a function of distance from the coast in the ocean directly south of Tema harbor for 17 August, 1972. Water temperature is taken at the surface, and air temperature $2 \mathrm{~m}$ above water surface.

rents throughout the year, and although it is not yet clear whether these represent a change in the mass flow or a local eddy, the data do not reveal any consistent correlation of the upwelling with ocean current or surface winds. We have at present, therefore, no satisfactory explanation for the upwelling off the Ghana coast and for the local mixing observed by Pople and Mensah (1971).
The author gratefully acknowledges the loyal assistance of Mr. William Asante who helped with the harbor measurements and the generous cooperation of the Ghana Meteorological Department and the Fishery Research Unit. Helpful criticisms of the original manuscript were made by Prof. A. D. Maude, Dr. Tom Beer and Dr. P. D. Berwick.

\section{REFERENCES}

Bakun, Andrew, Douglas R. McLain and Frank V. Mayo, 1973: Upwelling studies based on surface observations. Coastal Upwelling Experiment Workshop Abstracts, Dept. of Oceanography, Florida State University, Tallahasse.

BOMEX Bulletin No. 9, 1971 : BOMAP Office, U. S. Dept. of Commerce, NOAA, Rockville, Md.

Deardorff, James W., 1961: Local evaporation from a smooth water surface. J. Geophys. Res., 66, 529-531.

Ghana Fishery Research Unit, 1970: The NCOR report on the mechanism of the upwelling of Ghana's coastal waters. Marine Fishery Research Repts., No. 3, Tema, Ghana.

- 1973: Ocean currents measurements. Marine Fishery Research Repts. (in press).

Holland, J. Z., 1972: Comparative evaluation of some BOMEX measurements of sea surface evaporation, energy flux and stress. J. Phys. Oceanogr., 2, 476-486.

Ingham, M. C., 1970: Coastal upwelling in the northwestern Gulf of Guinea. Bull. Marine Sci., 20, 1-34.

Longhurst, A. R., 1964: The coastal oceanography of western Nigeria. Bull. l'Inst. Franc. d'Afrique Noire, 21, 337-402.

Penman, H. L., 1948: Natural evaporation. Proc. Roy. Soc. London, A193, 120-131.

Pople, W., and Mensah, M. A., 1971: Evaporation as the upwelling mechanism in Ghanaian coastal waters. Nalure, 234, 18-20.

Rohwer, C., 1931: Evaporation from free water surfaces. U. S. Dept. of Agriculture, Tech. Bull. No. 271.

U. S. Geological Survey, 1954: Water-loss investigations: Lake Hefner studies. Tech. Rept., Prof. Paper No. 270, U. S. Geol. Survey.

Webb, E. K., 1960: Evaporation from Lake Evcumbene. Tech. Paper No. 10, CSIRO Division of Meteorological Physics. 